\title{
Dijital Okuryazarlık ve Teknoloji Okuryazarlığı: Karşılaştırmalı Bir İnceleme ${ }^{\mathrm{a}}$
}

\author{
Yavuz Silik ${ }^{\mathrm{b}, \mathrm{c}}$, Fatih Aydın
}

\section{Özet}

$\mathrm{Bu}$ çalışmanın amacı, dijital ve teknoloji okuryazarlığına yönelik tanımlamaların tarihsel süreç içerisindeki değişimini karşılaştırmak, dijital ve teknoloji okuryazarı bireyler için tanımlanan özellikleri benzerlikler ve farklılıklar açısından incelemek ve bu okuryazarlıkların kapsamları bağlamında benzerliklerini ve farklılıklarını ortaya koymaktır. Çalışmada nitel araştırma yöntemi benimsenmiş ve doküman incelemesi yapılmıştır. Dokümanlara ulaşabilmek için taramada "teknoloji okuryazarlığı" ve "dijital okuryazarlık" kavramlarının yanında araştırmalarda anahtar kelime olarak sunulan "sayısal okuryazarlık", "bilgisayar okuryazarlığı" ve "bilgi ve iletişim teknolojileri okuryazarlığı" kavramları da kullanılmıştır. Sonuçta 86 makaleye ve 3 kitaba ulaşılmıştır. Detaylı analizden önce kaynaklar incelenmiş ve kapsamlı incelenmesi gereken 35 çalışma belirlenmiştir. Sonuçta, tarihsel süreç açısından gerek birbirlerinin yerine kullanımı gerekse alt boyutları bağlamında dijital ve teknoloji okuryazarlığı konusunda kavram kargaşası olduğu görülmüştür. İkincisi bu okuryazar bireyler için tanımlanan özelliklerin benzerliği kadar farklılıklarının da olduğu görülmüştür. Son olarak teknoloji ve dijital kavramları bağlamında bu okuryazarlıkların iç içe geçtiği ve bu anlamda kesin hatlarla ayrılmasının tam anlamıla mümkün olmadığı anlaşılmaktadır.
Anahtar Kelimeler

Dijital okuryazarlık

Teknoloji okuryazarlığı

Sayısal okuryazarlık

Bilgi ve iletişim teknolojileri okuryazarlığı.

Makale Hakkında

Geliş Tarihi: 01.04.2021

Kabul Tarihi: 15.12.2021

Doi: $10.18026 /$ cbayarsos. 907788

\section{Digital Literacy and Technological Literacy: A Comparative Examination}

\begin{abstract}
The aim of this study is to compare the changes in the definitions of digital and technological literacy in the historical process, to examine the characteristics defined for digital and technologically literate individuals in terms of similarities and differences, and to reveal the similarities and differences of these literacies in the context of their scope. The qualitative research method was adopted and document analysis was conducted. In addition to the concepts of "technological literacy" and "digital literacy"; the concepts "computer literacy" and "information and communication technologies literacy" are presented as keywords. As a result, 35 studies that need to be examined were determined. First, there is confusion in terms of digital and technological literacy by being used interchangeably. Second, the characteristics described for these literate individuals have differences as well as similarities. Finally, digital and technological literacy are intertwined and it is not possible to separate them with certain lines.
\end{abstract}

Keywords

Digital literacy

Technological literacy

Computer literacy

Information and communication technology literacy

About Article

Received: 01.04.2021

Accepted: 15.12.2021

Doi: 10.18026/cbayarsos. 907788

\footnotetext{
a Bu çalışma 13. Ulusal Fen Bilimleri ve Matematik Eğitimi kongresinde özeti yayımlanmış sözlü bildiri olarak sunulmuştur

b İletişim Yazarı: yavuz.silik@gmail.com

c Öğretmen, Iğdır İmam Hatip Ortaokulu, ORCID ID: 0000-0002-6346-1248

d Prof. Dr., Bolu Abant İzzet Baysal Üniversitesi, ORCID ID: 0000-0003-0453-5734
} 


\section{Giriş}

Yaşadığımız bilgi çağı içerisinde teknoloji sürekli ve geri dönülmez bir değişim ve dönüşüm içerisindedir. Özellikle dijital teknolojilerin günlük hayatımızdaki kullanımının büyük bir hız kazanması ve hayatımızın vazgeçilmez bir parçası olması ile birlikte öğrenme, zaman geçirme, iletişim kurma ve çalışma yöntemlerimize kadar birçok alanda büyük değiş̧iklikler meydana gelmiştir. Teknolojinin bu hızlı değişimi ve dönüşümü neticesinde bireylerin kazanması gereken beceriler de geçtiğimiz yüzyıla kıyasla büyük bir değişime uğramıştır (Ala-Mutka, 2008; Bakır, 2016; Dede, 2010). Techataweewan ve Prasertsin'in (2018) belirttiği gibi dijital okuryazarlık becerilerinin benimsenmesi, dijital öğrenme ortamı için temel bir sorundur. Bu değişen becerilerle birlikte 20. yüzyılın ortalarında tanımlanan geleneksel okuryazarlığın algısında bir kayma yaşanarak, yerine alternatif ve güncel okuryazarlık kavramları gelmiştir (Condy vd., 2012). Önceleri geleneksel okuryazarlık kavramının tanımı ve yaygın eğitim sistemlerinin temel amacı, öğrencileri kendi ana dillerinde okuma ve yazma becerisiyle donatmak iken; bu amaç 20. yüzyılın ortalarında sorgulanmaya başlamıştır (Kurt vd., 2014). 1960 ve 1970'li yıllarda gelişmekte olan ülkelerin teknolojik yeterlilik açısından "geride kalma" korkusu ile teknolojinin hızlı büyüme ve gelişme kat etmesiyle birlikte bilgisayar okuryazarlığı, dijital okuryazarlık, bilgi okuryazarlığı, teknoloji okuryazarlığı, bilgi ve iletişim teknolojileri okuryazarlığ üzere çeşitli bilişsel, duyuşsal ve psikomotor gibi yeterliklerin esas alındığ ortaya çıkmıştır (Leaning, 2019). Bunlardan bazıları tarih içerisinde kısa ömürlü olup, kısa sürede güncelliğini yitirirken bazıları ise günümüze kadar varlığını sürdürüp güncelliğini korumaya devam etmektedir. Güncelliğini koruyan bu kavramlardan ikisi teknoloji okuryazarlığı ve dijital okuryazarlık kavramlarıdır.

Teknoloji okuryazarlığı, son on yıldan bu yana insanın bilişsel ve psikomotor becerilerini içeren bir katalizör olarak görülmektedir (Crowe, 2006). Teknoloji okuryazarlığına yönelik anlayış, bir kişinin bir teknoloji uygulamasını kullanma becerilerinden ibaret değildir. Teknoloji okuryazarlığı, teknolojinin herhangi bir problemin çözümünde kullanılabilecek bir araç haline nasıl gelebileceğini düşünmenin bir yoludur (Herman, Maknun, Barliana ve Mardiana, 2018). En genel tanımıyla teknoloji okuryazarlığı, teknolojiyi kullanma, yönetme, değerlendirme ve anlama olarak tanımlanmaktadır (International Technology Education Association [ITEA], 2000). Dijital okuryazarlığın tanımlanmasında ise birçok belirsizlikler yer almaktadır (Bawden, 2008; Eshet-Alkalai, 2004; Norton ve Wiburg, 1998). Ayrıca uzmanlar (ör; Alkali ve Amichai-Hamburger, 2004; Bawden, 2008; Ng, 2012; Kazakoff, 2015) tarafından önerilen birçok dijital okuryazarlık bileşeni bulunmaktadır (Perdana, Yani, Jumadi ve Rosana, 2019). Örneğin Eshet-Alkalai (2004), dijital okuryazarlığı, aşağıdakileri içeren beş farklı okuryazarlığın bir derlemesi olarak tanımlayan kavramsal bir çerçeve sunmaktadır. Bunlar, foto-görsel okuryazarlık, yeniden üretim okuryazarlığı, bilgi okuryazarlığı, branşlaşmış okuryazarlık ve sosyo-duygusal okuryazarlıktır. Genel olarak dijital okuryazarlık ise aşağıdaki şu özelliklerle tanımlanabilir (Bakır, 2016; Milli Eğitim Bakanlığı [MEB], 2018):

a. Farklı dijital teknolojilerin bireylerin hem öğrenmelerini hem de kişisel gelişimlerini sağlayacak şekilde etkin, güvenli ve eleştirel bir şekilde kullanılması,

b. İhtiyaç duyulan bilginin fark edilmesi, tanımlanması, bu bilginin değerlendirilmesi ve kaydedilmesi, 
c. Mevcut bir bilgiden yeni ve özgün bilgi veya bilgiler elde edilmesi ve bu bilgilerin sunulmasi,

d. Güvenlik, ahlak ve yasal boyutlar çerçevesinde internet üzerinden ortak ağlara katılım sağlanarak iletişim kurulması, ticaret veya alışveriş gerçekleştirilmesidir.

Hem dijital okuryazarlık hem de teknoloji okuryazarlığ kavramlarının tarihsel süreçte gerek tanım boyutunda gerek ise kavramsal açıdan kesiştikleri önemli noktalar bulunmaktadır. Bu kavramların ne kadar örtüştükleri ve bu iki kavram arasında ne gibi farklılıklarının olduğunun araştırılması bu açıdan önem arz etmektedir. Dolayısıyla dijital ve teknoloji okuryazarlığı kavramlarının aynı şeyi ifade edip etmediği ve farklı yeterlikleri kapsayıp kapsamadığı önemli bir soru işareti olarak karşımıza çıkmaktadır. Bu çerçevede çalışmada;

1. Dijital okuryazarlığa ve teknoloji okuryazarlığına yönelik tanımlamaların tarihsel süreç içerisindeki değişimini karşılaştırmak,

2. Dijital ve teknoloji okuryazarı bireyler için tanımlanan özellikleri benzerlikler ve farklılıklar açısından incelemek ve

3. Teknoloji ve dijital okuryazarlıklarının kapsamları bağlamında benzerliklerini ve farklılıklarını ortaya koymaktır.

\section{Yöntem}

Çalışmada nitel araştırma yöntemi benimsenmiştir ve bu çerçevede doküman incelemesi (Patton, 2002; Corbin ve Strauss, 2008) yapılmıştır. Corbin ve Strauss (2008) doküman analizini sistematik bir prosedür olarak belirtmektedirler ve temel olarak şu üç süreci içerdiğini ifade etmektedirler. Bunlar; gözden geçirme (yüzeysel inceleme), okuma (kapsamlı inceleme) ve yorumlama sürecidir. Onlara göre bu yinelemeli bir süreçtir ve bu süreç içerik analizi ve tematik analiz unsurların birleştirir. Fereday ve Muir-Cochrane (2006) ise tematik analizin verilerde ortaya çıan bir form olduğunu ve bu temaların analiz kategorileri haline geldiğini ortaya koymuşlardır.

\section{Verilerin Toplanması}

Dokümanlara ulaşabilmek adına çalışmanın yapıldı̆̆ı Batı Karadeniz'de yer alan bir üniversiteye ait kütüphanenin abone olduğu veri tabanlarını tarama özelliğine sahip bir arayüzden faydalanılmıştır. Bu arayüz EBSCO, ERIC, ProQuest, Science Direct, Scopus, Springer Link, ULAKBIM ve Web of Science veri tabanlarını tek seferde tarayabilme imkânı sunmaktadır. Tarama çerçevesinin tanımlanması için temel kriterler üzerinden işlem yürütülmüştür. Buna göre öncelikle ilgili arayüz kullanılarak 1970 - 2020 yılları arasındaki dokümanlardan tarama yapılmıştır. İlgili arayüz kullanılarak yapılan tarama sonucunda 1970 tarihinden önce yapılmış bir çalışmaya rastanmamıştır. Bu nedenle 1970 yılı en eski tarih olarak belirtilmiştir.Tarama işlemi 2020 yılının temmuz ayı sonunda gerçekleştirildiğinden en son tarih olarak ta 2020 yılı olarak ifade edilmiştir. Taramalar araştırmacılar tarafından aynı arayüz üzerinden birlikte gerçekleştirilmiştir. Bu taramada "teknoloji okuryazarlığı" ve "dijital okuryazarlık" kavramlarına ek olarak bu kavramlar ile ilgili araştırmalarda anahtar kelime olarak sunulan "sayısal okuryazarlık", "bilgisayar okuryazarlığ1" ve "bilgi ve iletişim teknolojileri okuryazarlığı" kavramları da Türkçe ve İngilizce olarak her iki dilde de kullanılmıştır. Taramada ulaşılabilir tam metin çalışmalar filtrelenmiştir. Tarama sonucunda 
doğrudan ilgili konuda yazılmış, Amerika (25), Türkiye (19), İsrail (9), İngiltere (7), Kanada (7), İskoçya (5), Avustralya (4), Çin (3), İrlanda (2), Güney Afrika (2), Endonezya (2), İspanya (1), Polonya (1), Tayland (1), Norveç (1) ülkeleri kaynaklı toplam 86 tam metin makaleye ve 3 kitaba ulaşılmıştır. Dokümanların detaylı analizi yapılmadan önce Corbin ve Strauss (2008) tarafından belirtildiği şekliyle öncelikle ulaşılan kaynaklar yüzeysel olarak incelenmiştir. Bu yüzeysel inceleme detaylı incelemeyi gerektiren çalışmaları belirlemek için gerçekleştirilmiştir. Bu süreçte dahil edilen ve hariç tutulan ölçütler tablo 1'de sunulmuştur.

Tablo 1. Dâhil edilen ve hariç tutulan ölçütler

\begin{tabular}{lll}
\hline Ölçütler & Dahil edilen & Hariç tutulan \\
\hline Tarih & 1970-2020 arası kayıtlar & $\begin{array}{l}1970 \text { öncesi ve 2020 (Temmuz) sonrası } \\
\text { kayıtlar }\end{array}$ \\
\hline Dil & Türkçe ve İngilizce yayımlanmış kayıtlar & Diğer dillerde yayımlanmış kayıtlar \\
\hline Tam Metin & Tam metin kayıtlar & Özet olarak sunulan kayıtlar \\
\hline Kapsam & Doğrudan bu okuryazarlıklar üzerine & Bu okuryazarlıkların bir konunun \\
& çalışılmış kayıtlar & değikeni olarak çalışıldığı kayıtlar \\
& Bu okuryazarlıklar üzerine net bir tanım & $\begin{array}{l}\text { Bu okuryazarlıklarla ilgili bir tanım } \\
\text { sunmanan kayıtlar }\end{array}$ \\
& sunan kayıtlar & $\begin{array}{l}\text { Belli spesifik bir gruba odaklanılarak } \\
\text { çerçevesi oluşturulan kayıtlar }\end{array}$ \\
& &
\end{tabular}

Tablo 1'de yer alan tarih, dil ve tam metin ölçütleri, çalışmalara ilk ulaşım sürecinde ilgili arayüzün özelliği kullanılarak dikkate alınmıştır. Sonrasında kapsamı bağlamında çalışmalar incelenmiştir. Buna göre ilk olarak ilgili çalışmanın kapsamlı bir şekilde ilgili okuryazarlıkların tanımını içerip içermediğine bakılmıştır. İlgili çalışmada okuryazarlıklar bir konunun değişkeni olarak ele alındıysa (örneğin, katılımcı seçimi bağlamında teknoloji ya da dijital okuryazarı bireylerin belirlenmesi) incelemeye dahil edilmemiştir. İkincisi, doğrudan bu okuryazarlıklar üzerine bir çerçeve çizen (örneğin, durum tespiti, katılımcıların bu konulardaki becerileri ve yetenekleri gibi) diğer bir ifade ile çalışmanın amacını oluşturan çalışmalar incelemeye dahil edilmişlerdir. Ancak bu süreçte belli bir gruba odaklanılarak hazırlanan çalışmalar hariç tutulmuştur. Bu ölçütler çerçevesinde araştırmanın amaçlarına cevap verecek nitelikte olduğu görülen ve detaylı incelemeyi gerektiren Türkiye (12), Amerika (5), İngiltere (4), İsrail (3), Kanada (2), İskoçya (1), Avustralya (1), Çin (1), İrlanda (1), Güney Afrika (1), İspanya (1) ülke kaynaklı 32 makale araştırmacılar tarafından belirlenmiştir. Makaleler haricinde ulaşılan Amerika kaynaklı 3 kitap da yukarıda belirtilen dahil edilme ölçütlerini taşıdığından incelemeye alınmıştır. Bu sürece ilişkin genel bir bakış Şekil 1' deki akış diyagramında sunulmuştur. 


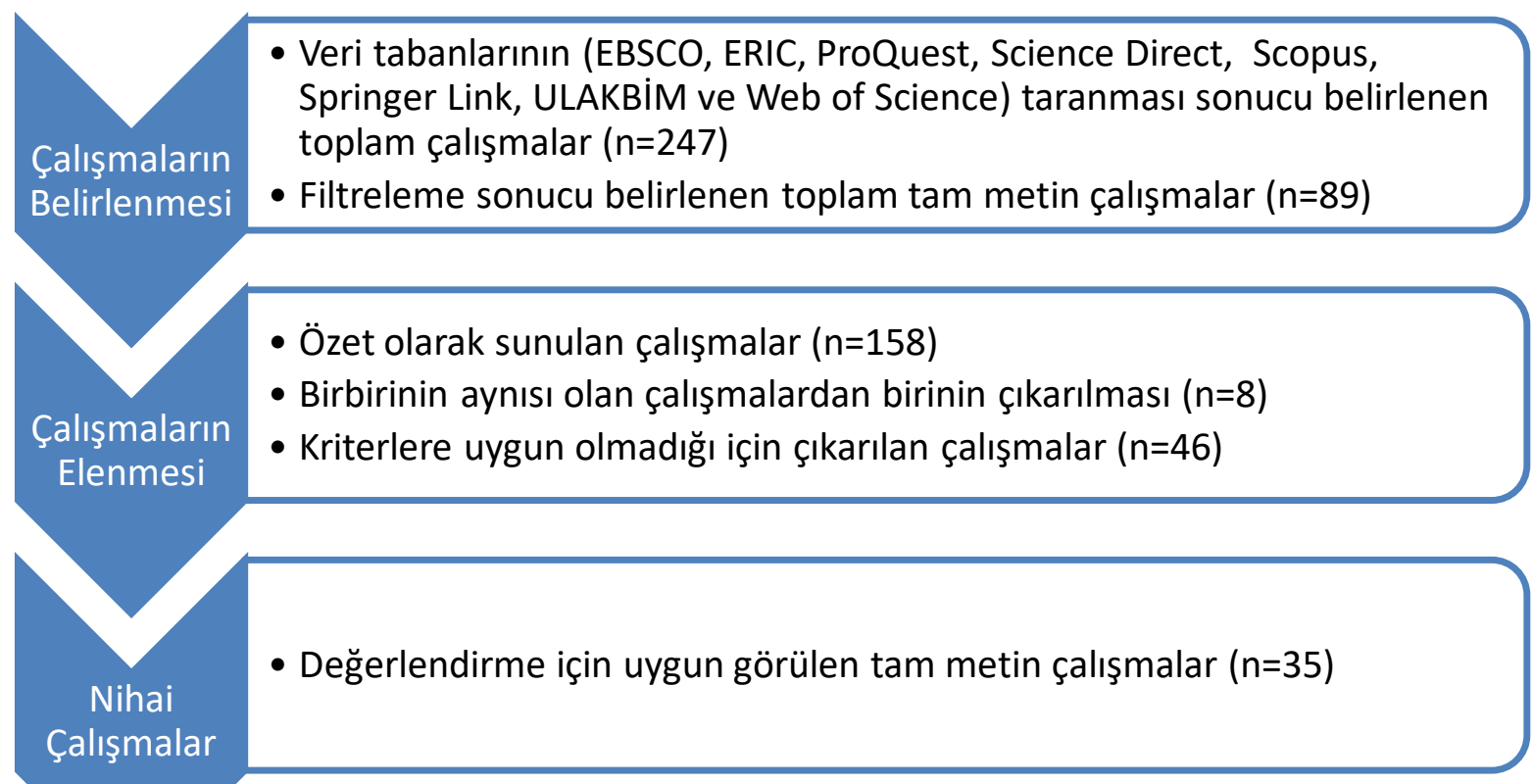

Şekil 1. Veri toplama sürecine ilişkin akış diyagramı

\section{Verilerin Analizi}

Çalışmada belirtilen her bir amaç bir tema olarak dikkate alınmıştır. İlgili çalışmaların analizleri ayrı ayrı her tema altında araştırmacılar tarafından birarada betimsel analizle yapılmıştır. Araştırmacılar bu tür birçok benzer çalışmalarda yer almış ve analiz süreçlerine dahil olmuşlardır. Bu haliyle yeterli uzmanlığa sahip oldukları değerlendirilebilir.-Betimsel analiz yapılırken ilgili temayı karşılayan bölümler "dijital okuryazarlık" ve "teknoloji okuryazarlığı" kodlamalarıyla tanımlanmıştır. Böylece betimsel analiz sayesinde bulgular, bu kavramların makalelerde doğrudan yer aldığı haliyle belirlenmiştir. Analiz süreci, veriler ile yorumlar arasında devamlı gidip gelinerek yinelemeli bir süreç olarak (Aspers ve Corte, 2019) gerçekleştirilmiştir. Bu yinelemeli süreçte aynı bulgulara ulaşılmıştır ve dolayısıyla araştırmacılar arasında görüş birliği olacak şekilde analizler tamamlanmıştır.

\section{Geçerlik ve Güvenirlik}

Çalışmanın iç geçerliği, ilgili alanda çalışmaları bulunan iki uzmanın gerek veri toplama yolları gerekse bulgular üzerine görüşleri alınarak sağlanmıştır (Merriam, 1998). Çalışmanın güvenirliği ise tekrarlı olarak aynı bulgulara ulaşılması ile sağlanmıştır. Çünkü Yin (2018) tarafından da ifade edildiği üzere çalışmanın güvenirliği, bu çalışmanın işlemlerinin açıkça tanımlanmış olması ve aynı sonuçlarla tekrarlanabileceğinin gösterilmesidir. Bununla birlikte Guba ve Lincoln (1982) geçerlik ve güvenirlik terimlerine naturalistik paradigma bağlamında dört terim önermektedirler. Bunlar, inanılırlık, aktarılabilirlik, güvenilebilirlik ve onaylanabilirliktir. Çalışmada inanılırlığı sağlamanın yollarına Holloway ve Wheeler (1996) uzun süreli etkileşim ve uzman incelemesini örnek göstermektedir (Başkale, 2016). Bu çalışmada da inanırlığı sağlamak için analiz sürecinde de belirtildiği üzere uzmanlarla birlikte ilgili çalışmalarla uzun süreli yinelemeli bir süreç izlenmiştir. Böylece çalışmalara tam anlamıyla vakıf olunmuştur. Aktarılabilirlik için, ulaşılan çalışmaların incelemeye dahil 
edilme ve incelemeden hariç tutulma ölçütleri net bir şekilde ortaya konmuştur. Ayrıca çalışmanın amacına yönelik elde edilen sonuçlar ayrıntılı bir şekilde sunulmuştur (Başkale, 2016). Güvenilebilirlik, araştırma sürecinin ayrıntılı ve açık bir şekilde sunulmuş ve tekrarlanabilir olmasını gerektirir (Arastaman, Öztürk Fidan ve Fidan, 2018). Bu çalışmada da tüm süreç ayrıntıları ile sunulmuştur ve özellikle analiz kısmında belirtilen yinelemeli çalışma ile ulaşılan benzer bulgular güvenilebilirliğin sağlandığını göstermektedir. Çalışmanın onaylanabilirliği ise önyargıların azaltılarak objektifliğin artırılmasını gerektirir (Başkale, 2016). Bu çalışmada da onaylanabilirliği sağlamak adına bulgular, araştırmacıların yorumlarıyla değil, doğrudan ilgili çalışmalarda yer alan tanımlamaların sunumuyla gerçekleştirilmiştir.

\section{Sinirliliklar}

Çalışmamızda veri tabanlarını tek seferde tarayabilme özelliğine sahip bir arayüzün kullanılması ve Web of Science, Scopus, Science Direct gibi önemli veri tabanlarına ulaşılabilir olunması verilere ulaşmanın güçlü bir yanı olarak değerlendirilebilir. Ancak bununla birlikte bazı sınırlılıklar göz önüne alınabilir. İlk olarak bu çalışma kullanılan bu arayüzle sınırlıdır. $\mathrm{Bu}$ arayüzle yapılan tarama ile veri tabanları üzerinde ayrı olarak yapılan taramalarda aynı sonuçlara ulaşılmaktadır. Bu nedele ilgili veri tabanları ayrı ayrı taranmamıştır. Bir diğeri ise, bu arayüzle yapılan taramada en eski 1970 yılına ulaşılabildiğinden incelemeler bu tarihe kadarki çalışmalarla sınırlı kalmıştır. Ayrıca taramalar belirtilen anahtar kelimelerle sınırlıdır ve araştırmacılar tarafından gerçekleştirilmiştir. Araştırmacılar taramayı 2020 yılının temmuz ayının sonunda ilgili anahtar kelimeleri kullanarak gerçekleştirdiğinden ulaşılan kayıtlar bu anahtar kelimelerle ve bu tarihe kadar ulaşılan çalışmalarla sınırlıdır. Bunun yanında çalışmanın tam metin makaleler üzerinden yürütülmesi dolayısıyla tam metnine ulaşılamayan çalışmaların kapsam dışı bırakılması bir sınırlılık olarak değerlendirilebilir. Sonuç olarak bu çalışma ulaşılabilir tam metin makalelerle sınırlıdır. Diğer yandan çalışmada, ulaşılabilir tam metin makaleler üzerinden analizler gerçekleştirildiğinden elde edilen bulgular ve karşılaştırmalar da bu makalelerle sınırlıdır. Çünkü analizi yapılan tam metin makalelerde uygulamaya ve araştırmaya yönelik içerikler (dijital ve teknoloji okuryazarı bireylerin özellikleri gibi) yer almaktadır ve dolayısıyla kendi metodolojik çalışmalarının sonuçlarını sunmaktadırlar. Son olarak incelenen çalışmalar yukarıda belirtilen eleme ölçütleriyle sınırlıdır. Böylece çalışmada belli bir bağlam oluşturulması hedeflenmiştir.

\section{Bulgular}

\section{Tarihsel Süreçte Dijital ve Teknoloji Okuryazarlı̆̆ına Yönelik Tanımlamalar}

Dijital okuryazarlık ve teknoloji okuryazarlığına ait çalışmalar her ne kadar son 10-15 yıl içerisinde büyük hız kazansa da bu iki kavram 20. yüzyılda ortaya çıkan kavramlardır. Teknoloji okuryazarlığı ilk olarak 1920'li yıllarda ABD'de teknoloji eğitiminin temelini oluşturan endüstriyel eğitim ve görsel-işitsel eğitim ile ortaya çıkmıştır (Petrina, 2003). Teknoloji okuryazarlığının da habercisi olan endüstriyel eğitim, ülkenin işçi sınıfını ve yeni endüstriyel teknolojilere yönelik gereksinimleri karşılamak için öğrenme ortamı içerisine dâhil edilmiştir. Amaç, o günlerde çoğunlukla erkek olmak üzere işçi sınıfı çocuklara sanayileşmenin etkileri karşısında ihtiyaç duydukları bilgi, beceri ve değerleri sağlamaktı (Petrina, 2003). 
1980'lerin ortalarına gelindiğinde ise eğitim teknologları, ilgi alanlarının görsel işitsel eğitim ve endüstriyel eğitimden "bilgisayar okuryazarlığı" eğitimine dönüşmesiyle teknoloji eğitimcileri haline gelmiştir (Leaning, 2019). Bu dönemde "bilgisayar okuryazarlı̆̆ı", dijital okuryazarlığın başlangıcı olarak kabul edilen (Buckingham, 2008) ve aynı zamanda teknoloji okuryazarlığı ile aynı anlamı teşkil eden bir kavram olarak kullanılmıştır. Dijital okuryazarlığın 1997 yılında yayımlanan Paul Gilster'ın "Digital Literacy" kitabında ifade edilmesinden önce 1980'li yıllarda "bilgisayar okuryazarlığı" şeklinde ortaya çıktığı burada görülmektedir. Bilgisayar okuryazarlığı, teknoloji okuryazarlığı ile eş anlamlı olarak kullanılmaktadır ve bilgisayarları kullanması için bir kişide olması gereken bilgi ve yetenek şeklinde tanımlanmaktadır (Mc-Millan, 1996; National Research Council Committee, 1999). Gilster (1997) ise dijital okuryazarlık kavramını, bilgisayarlar aracılığıyla sunulduğunda çok çeşitli kaynaklardan gelen birden çok formatta bilgiyi anlama ve kullanma yeteneği olarak tanıtmaktadır. 80'li yıllarda ise bilgisayar okuryazarlığ programlama üzerinde durulmuştur (Petrina, 2003). Öte yandan teknoloji okuryazarlığ $90^{\prime} l_{1}$ yıllarda "geniş bir perspektiften her vatandaşın teknolojinin doğası, davranışı, gücü ve sonuçları hakkında bir dereceye kadar bilgi sahibi olması (ITEA, 1996, s. 1)" şeklinde tanımlanmıştır.

Teknoloji okuryazarlığının, bilgi ve iletişim teknolojisi okuryazarlığına ait tanım ile eşanlamlı olarak kullanıldığ1 ve teknolojiyi kullanarak bilgi toplama, organize etme, analiz etme ve raporlama becerisi şeklinde tanımlandığı çalışmalara da rastlanılmaktadır (Leu ve Kinzer, 2000). Güneş ve Bahçivan (2017) ise çalışmasında, dijital okuryazarlığa alternatif kavram olarak bilgi ve iletişim teknolojileri okuryazarlığını kullanmıştır. Burada ifade edilen dijital okuryazarlık, öğretimi iyileştirmek adına teknoloji kullanımını, teknolojiye ve onun uygulamalarına yönelik pozitif tutumu, teknolojik araçlara karşı aşina olmayı, yeterli düzeyde teknik, bilişsel ve sosyo-duyuşsal becerileri içermektedir. Nitekim dijital okuryazarlık 2000'li yıllarda Eshet-Alkalai (2004) tarafından "Dijital teknolojinin hızlı ve sürekli gelişiminin ışığında, bireylerin, dijital ortamlarda görevleri yerine getirmek ve sorunları çözmek için artan çeşitlilikte teknik, bilişsel ve sosyolojik becerileri kullanmaları (s.93) " olarak tanımlanmıştır. Dijital okuryazarlığına ve teknoloji okuryazarlığına yönelik tanımlamaların tarihsel süreç içerisindeki değişimini gösteren karşılaştırma Tablo 2' de sunulmaktadır.

Tablo 2. Dijital okuryazarlığına ve teknoloji okuryazarlığına yönelik tanımlamaların tarihsel süreç içerisindeki değişimin karşılaştırılması

\begin{tabular}{|c|c|c|}
\hline Tarih Aralığ & Teknoloji Okuryazarlığı & Dijital Okuryazarlık \\
\hline 1920-1980 yılları arası & $\begin{array}{l}\text { Endüstriyel eğitim ve görsel işitsel } \\
\text { eğitim (Petrina, 2003) }\end{array}$ & - \\
\hline $80^{\prime}$ li yıllar & $\begin{array}{l}\text { Bilgisayar } \\
\text { (Buckingham, 2008; Childers, 2003; } \\
\text { Mc-Millan, 1996; National Research } \\
\text { Council Committee, 1999) }\end{array}$ & $\begin{array}{l}\text { Bilgisayar } \quad \text { okuryazarlığ1 } \\
\text { (Buckingham, 2008) }\end{array}$ \\
\hline 90'li y1llar & $\begin{array}{l}\text { Teknoloji Okuryazarlığı (Technology } \\
\text { for All Americans [TfAAP], 1996) }\end{array}$ & $\begin{array}{l}\text { Dijital Okuryazarlık (1997 yılı ve } \\
\text { sonrası) (Gilster, 1997) }\end{array}$ \\
\hline
\end{tabular}


2000'li yıllar
Teknoloji Okuryazarlığı, Bilgi ve iletişim teknolojisi okuryazarlığı (Leu ve Kinzer, 2000)
Dijital Okuryazarlık, Bilgi ve iletişim teknolojisi okuryazarlığ 1 (Güneş ve Bahçivan, 2017)

Tablo 2' de, dijital okuryazarlık ve teknoloji okuryazarlığına yönelik tanımlamaların tarihsel süreç içerisindeki değişimi karşılaştırıldığında; teknoloji okuryazarlığının 1920-1980 yılları arasında endüstriyel eğitim ve görsel işitsel eğitim bağlamında kullanılırken 2000'li yıllarda bilgi ve iletişim teknolojisi okuryazarlığı olarak ifade edildiği görülmektedir. Yine 80'li yıllarda bilgisayarların gelişimi ile ortaya çıkan bilgisayar okuryazarlığının da, ilk kez 90'lı yıllarda dijital okuryazarlık olarak değiştiği 2000'li yıllarda da bilgi ve iletişim teknolojisi okuryazarlığı olarak ifade edildiği görülmektedir.

\section{Dijital ve Teknoloji Okuryazarı Bireyler için Tanımlanan Özellikler}

$\mathrm{Bu}$ bölümde dijital ve teknoloji okuryazarı bireylerin benzer ve farklı özellikleri ayrı ayrı başlıklar halinde ele alınmıştır.

\section{Dijital ve Teknoloji Okuryazarı Bireylerin Benzer Özellikleri}

Çalışmalarda dijital ve teknoloji okuryazarı bireylerin benzer özellikleri şu şekilde ifade edilmektedir. Teknoloji ve dijital okuryazarı bireyler, teknolojiye merak duyan, teknolojiye kolay uyum sağlayan aynı zamanda teknolojiyi etkili ve verimli bir şekilde kullanan bireylerdir (Ng, 2012; Üstündağ, Güneş ve Bahçivan, 2017; Yıldız, Kahyaoğlu ve Kaya, 2012). Her iki okuryazar da teknolojiyi etkili ve verimli bir şekilde kullanabilen, eleştirel ve analitik düşünebilen, etkin değerlendirme yapabilen ve problem çözme becerilerini kullanabilen bireylerdir (Akkoyunlu ve Soylu, 2010).

Bennett, Wells ve Rank (2009) tarafından belirtildiği gibi teknoloji okuryazarı mükemmel bir problem çözücüdür, bilgiyi yayınlayabilir ve üretebilir ve yaratıcı araçların verimli bir kullanıcısıdır. Yine Media Awareness Network (2010) tarafından da belirtildiği gibi dijital okuryazarlık içerisinde çeşitli dijital ortam yazılım uygulamalarını ve donanım aygıtlarını kullanma becerisi ve bilgisi, dijital medya içeriğini ve uygulamalarını eleştirel olarak anlama becerisi ve dijital teknoloji ile yaratma bilgi ve kapasitesi yer almaktadır.

Teknoloji okuryazarlığı, özellikle eğitim dünyasında insan teknolojisini/yenilikçiliğini etkin bir şekilde kullanma çabası içinde bilim, eleştirel düşünme becerileri ve karar verme yönlerinden oluşan bir yetenek olarak yorumlanabilir (Herman, Maknun, Barliana ve Mardiana, 2018). Teknoloji okuryazarı olan bir kişi, teknolojik bilgileri kavrama ve verilen görevleri başarıyla tamamlama potansiyeline sahiptir. Elde edilen teknolojik bilgilerin sürekli bir kullanıcısı, düzenli bilgi arayan, analizci, değerlendirici ve etkili bir iletişimcidir. Teknoloji okuryazarı bir kişi bilgiye erişme, onu yönetme, kullanma, analiz etme ve değerlendirme becerisine sahiptir (Pearson ve Young, 2002). Benzer şekilde dijital okuryazarlık ta, eleştirel düşünme becerileri, yaratıcılık, bilgiyi oluşturma ve değerlendirme, dijital medyayı etkin bir şekilde kullanma gibi çeşitli unsurlara sahiptir ve öğrencilerin dijital yazımının bir sonucu olarak geliştirilebilir (Al-Qallaf ve Al-Mutairi, 2016). Dijital ve teknoloji okuryazarı bireylerin benzer özellikleri Tablo 3'te sunulmaktadır. 
Tablo 3. Dijital ve teknoloji okuryazarı bireylerin benzer özellikleri

Teknolojiye merak duyarlar (Ng, 2012; Üstündağ, Güneş ve Bahçivan, 2017; Yıldı, Kahyaoğlu ve Kaya, 2012).

Teknolojiye kolay bir şekilde uyum sağlarlar (Ng, 2012; Üstündağ, Güneş ve Bahçivan, 2017)

Teknolojiyi etkili ve verimli bir şekilde kullanırlar (Akkoyunlu ve Soylu, 2010; Al-Qallaf ve Al-Mutairi, 2016; Media Awareness Network, 2010)

Eleştirel ve analitik düşünme becerisine sahiptirler (Al-Qallaf ve Al-Mutairi, 2016; Herman, Maknun, Barliana ve Mardiana, 2018; Pearson ve Young, 2002)

Bilgiye erişme, onu yönetme, kullanma, analiz etme ve değerlendirme becerisine sahiptirler (Al-Qallaf ve Al-Mutairi, 2016; Pearson ve Young, 2002).

Problem çözme becerileri gelişmiştir (Akkoyunlu ve Soylu, 2010; Bennett, Wells ve Rank, 2009)

Tablo 3'e bakılarak dijital ve teknoloji okuryazarı bireylerin özellikleri benzerlik açısından inclendiğinde; dijital ve yeknoloji okuryazarı bireyler, farklı dijital teknolojilere merak duyup, bu teknolojilere kolay bir şekilde uyum sağlayan, farklı dijital teknolojileri etkili ve verimli bir şekilde kullanan, eleştirel, analiz ve problem çözme becerileri gibi üst bilişsel becerilere sahip, dijital teknolojileri kullanarak bu teknolojiler ile bilgi edinme, edindikleri bu bilgiyi yönetme, kullanma, analiz etme ve değerlendirme becerisine sahip bireylerdir.

\section{Dijital ve Teknoloji Okuryazarı Bireylerin Farklı Özellikleri}

Dijital okuryazarı ve teknoloji okuryazarı bireylerin benzerlikleri kadar farklılıklarının da bulunduğu anlaşılmaktadır. Şöyle ki, teknoloji okuryazarı bireyler teknolojinin temel kavramlarını bilmekle beraber teknolojinin doğasını ve teknolojinin bireyle, toplumla ve çevrele ilişkisini de iyi bir şekilde bilen kişiler olarak tanımlanmaktadır (Bacanak, Karamustafaoğlu ve Köse, 2003; ITEA, 2000; TfAAP, 1996). Dijital okuryazarı bireyler ise yukarıda belirtilen bu yeterliklerden daha çok dijital araçlar üzerinden doğru bilgi edinme sürecini gerçekleştiren, internet üzerinden gerek iletişim kurmada gerekse ticaret konusunda ahlak kurallarını ve yasaları bilen ayrıca bu konuda sorumluluklarını yerine getiren bireyler olarak belirtilmektedir (Bakır, 2016; MEB, 2018). Öğrenme için dijital okuryazarlık, teknolojinin nasıl kullanılacağını bilmekten daha fazlasıdır, aynı zamanda doğru bilgi yönetimi ve eleştirel düşünme becerilerinin yanı sıra uygun çevrimiçi davranışa sahip olmaktır (Tang ve Chaw, 2016).

Teknoloji okuryazarı bireylerin dijital okuryazarı bireylerden farklılık gösterdiği başka bir önemli nokta daha vardır. Teknoloji okuryazarlığ (bilim/temel teknolojik yetkinlik) açısından değerlendirildiğinde öğrencilerin, insanların istek ve ihtiyaçlarını karşılama noktasında bilgi ve yöntemleri uygulaması, insan eliyle doğada meydana gelen değişimleri ve bu değişimler karşısında sorumluluklarını kavraması beklenmektedir. Dijital okuryazarlık (dijital yetkinlik) açısından ise öğrencilerin, bilgi ve iletişim teknolojilerini etkin, güvenli ve eleştirel bir şekilde kullanarak bilgiye erişmesi ve onu değerlendirmesi, bilgiyi kaydetmesi, yeni ve özgün bir bilgi üretmesi ve sunması, bunun dışında internet üzerinde ortak ağlara katılım sağlaması ve iletişim kurması, güvenli bir şekilde internet üzerinde alışveriş gerçekleştirebilmesi 
beklenmektedir (MEB, 2018). Dijital ve teknoloji okuryazarı bireylerin farklı özelliklerine yönelik karşılaştırma ise Tablo 4 'te sunulmaktadır.

Tablo 4. Dijital ve teknoloji okuryazarı bireylerin farklı özellikleri

\begin{tabular}{|c|c|}
\hline Teknoloji Okuryazan Bireyler & Dijital Okuryazarı Bireyler \\
\hline $\begin{array}{l}\text { Teknoloji ile ilgili temel kavramları ile birlikte } \\
\text { teknolojinin doğasını bilirler ve fen-teknoloji- } \\
\text { toplum-çevre (FTTÇ) ilişkisini iyi bir şekilde } \\
\text { anlarlar ve sorumluluklarını yerine getirirler } \\
\text { (Bacanak, Karamustafaoğlu ve Köse, 2003; } \\
\text { ITEA, 2000; TfAAP, 1996). }\end{array}$ & $\begin{array}{l}\text { Teknoloji ile ilgili temel kavramları bilirler } \\
\text { (MEB, 2018). }\end{array}$ \\
\hline $\begin{array}{l}\text { Farklı dijital araçları etkili bir şekilde } \\
\text { kullanırlar (ITEA, 2000). }\end{array}$ & $\begin{array}{l}\text { Farklı dijital araçları etkili bir şekilde } \\
\text { kullanırken yasal, etik ve ahlaki çerçevede } \\
\text { kullanımına daha çok dikkat ederler (Acar, } \\
\text { 2015; Bakır, 2016; MEB, 2018; Tang ve Chaw, } \\
\text { 2016). }\end{array}$ \\
\hline
\end{tabular}

Tablo 4'e bakılarak dijital ve teknoloji okuryazarı bireyler için tanımlanan farklı özellikler incelendiğinde; teknoloji okuryazarı bireyler, teknolojinin doğası hakkında bilgi sahibi ve FTTÇ (fen-teknoloji-toplum-çevre) kavramları arasında ilişki kurabilirken; dijital okuryazar bireyler farklı dijital araçları kullanırken yasal, etik ve ahlaki kullanıma daha çok dikkat eden bireylerdir.

\section{Okuryazarlıkların Kapsamları Bağlamında Benzerlikleri ve Farklılıklan}

$\mathrm{Bu}$ bölümde de yine okuryazarlıkların kapsamları bağlamında benzerlikleri ve farklılıkları ayrı ayrı başlıklar halinde sunulmuştur.

\section{Kapsamları Bağlamında Okuryazarlıkların Benzerlikleri}

Dijital ile teknoloji okuryazarlığı, aralarında net bir ayrımın olmadığı ve birbiri ile etkileşim içerisinde olan iki kavramdır. Kurt vd. (2014) dijital okuryazarlık, teknoloji okuryazarlığı, bilgisayar okuryazarlığı, medya okuryazarlığı ve bilgi okuryazarlığı gibi okuryazarlık alanlarının her birinin birbiri ile etkileşim içerisinde olduğunu ve bu okuryazarlıklar arasında kesin bir ayrımın bulunmadığını ifade ederek dijital ve teknoloji okuryazarlığı kavramlarının birbiri ile iç içe kavramlar olduğunu belirtmektedir. Bu açıklamaya benzer şekilde Ribble ve Bailey (2007) dijital okuryazarlığı, dijital teknolojileri nasıl ve ne zaman kullanacağını bilme yeteneği şeklinde tanımlamaktadır. Ribble, Bailey ve Ross (2004) “Teknolojiyi ne zaman ve ne şekilde kullanmalıyız?" sorusunun cevabını bulmak için teknoloji okuryazarı olmanın önemli olduğunu belirterek bu iki kavramın birbiri ile ne kadar iç içe bir kavram olduğunu göstermektedir (Bakır, 2016).

Hem dijital okuryazarlık hem de teknoloji okuryazarlığı 21. yüzyıl hayatta kalma becerilerindendir (Eshet-Alkalai, 2004; Martin, 2005; The North Central Regional Educational 
Laboratory [NCREL], 2003). Martin (2005) dijital okuryazarlık kazanılmadan insanların ne toplum yaşamına katılabileceğini ne de 21. yüzyılda yaşamak için gerekli olan bilgi ve beceriyi elde edebileceğini ifade etmiştir. NCREL (2003) ise içinde bulunulan dijital çağda, öğrencilerin yaşamak, öğrenmek ve başarılı bir şekilde çalışabilmeleri için teknoloji okuryazarı olmaları gerektiğini açıklamaktadır.

Tarihsel süreç içerisinde her iki okuryazarlıkta da tek boyutluluktan çok boyutluluğa doğru bir geçiş söz konusudur. 1980'li yıllarda her iki okuryazarlık da bilgisayar kullanma becerisini ifade ederken 90'lı yıllardan itibaren teknoloji okuryazarlığının kapsamı, farklı teknoloji araçlarının Fen, Teknoloji, Mühendislik, Matematik, Sosyal ve Beşeri Bilimler, Dilbilgisi vb. disiplinler arası ilişkiyi sağlayacak şekilde genişlemiştir (ITEA, 2000). Dijital okuryazarlık ise bilgisayar dâhil farklı dijital teknolojilerin kullanılarak doğru bilgiye ulaşma, düzenleme, geliştirme, değerlendirme, yeni bir bilgi elde etme ve sunma boyutunda genişleme sağlamıştır (Hamutoğlu vd., 2017; Timur, Timur ve Akkoyunlu, 2014). Bunula birlikte her iki okuryazarlık da ilgili olunan teknolojiye dair bilgi, beceri ve tutum gerektirmektedir (Buckingham, 2008; $\mathrm{Ng}$, 2012; Wang, 2003). Kapsamları bağlamında dijital ve teknoloji okuryazarlıklarının benzerlikleri Tablo 5'de sunulmaktadır.

Tablo 5. Kapsamları Bağlamında Dijital ve Teknoloji Okuryazarlıklarının Benzerlikleri

Dijital ve teknoloji okuryazarlığı kavramları, birbiri ile kesin ayrımı olmayan içiçe kavramlardır (Bakır, 2016; Kurt vd., 2014).

21. yüzyıl hayatta kalma becerileri arasındadırlar (Eshet-Alkalai, 2004; Martin, 2005; NCREL, 2003).

Tarihsel açıdan her iki okuryazarlıkta da tek boyutluluktan çok boyutluluğa doğru bir geçiş vardır (Hamutoğlu vd., 2017; ITEA, 2000; Timur, Timur ve Akkoyunlu, 2014).

İlgili teknolojiye dair bilgi, beceri ve tutum gerektirirler (Buckingham, 2008; Ng, 2012; Wang, 2003).

Tablo 5'e göre kapsamları bağlamında dijital ve teknoloji okuryazarlıklarının benzerlikleri incelendiğinde; iki okuryazarlık da birbiri ile etkileşim halinde olan, ilgili teknolojiye dair bilgi, beceri ve tutum gerektiren ve 21. yüzyıl için kazanılması gereken kavramlardır. Tarihsel açıdan bu iki kavram incelendiğinde ise iki kavramda da tek boyutluluktan çok boyutluluğa geçiş söz konusudur.

\section{Kapsamları Bağlamında Okuryazarlıkların Farklilıkları}

Teknoloji ve dijital okuryazarlığı ele alındığı boyutlar açısından incelenecek olursa, teknoloji okuryazarlığ1 genel olarak bilgi, eleştirel düşünme ve karar verme ve yetenekler boyutunda (Knieová vd., 2016; Shackelford, 2007; Yiğit, 2011) ele alınırken, dijital okuryazarlık bilişsel, teknik (psikomotor) ve sosyo-duyuşsal boyutlar açısından (Eshet, 2002; Ng, 2012) ele alınmaktadır. Bu boyutlar içerisinde yer alan yeterlikler açısından bu iki okuryazarlık kıyaslandığında ise teknoloji okuryazarlığında teknolojiye dair tasarım, tasarlanmış dünya süreci yer alırken (Bacanak, Karamustafaoğlu ve Köse, 2003) dijital okuryazarlıkta tasarım süreci yer almamaktadır. Dijital okuryazarlıkta ise dijital araçların yasal, etik ve ahlaki 
çerçevede kullanımı daha çok dikkate alınırken (Acar, 2015) teknoloji okuryazarlığında bu faktörler dikkate alınmamaktadır.

Özellikle 2000'li yıllarda gerçekleştirilen çalışmalarda bu okuryazarlıklarla ilgili farklı konumlandırmalar yapılmaktadır. Bu bağlamda gerek teknoloji okuryazarlığının dijital okuryazarlığın bir alt boyutu gerekse dijital okuryazarlığın teknoloji okuryazarlığının bir alt boyutu olarak konumlandırıldığı görülmektedir. Aynı zamanda teknoloji okuryazarlığının dijital okuryazarlığa alternatif bir kavram olarak kullanıldığı çalışmalara da rastlanmaktadır. Örneğin Kıyıcı (2008), dijital okuryazarlığın tek bir okuryazarlık çeşidi olmadığını bunun yanında teknoloji okuryazarlığı, bilgisayar okuryazarlığı, medya okuryazarlığı ve bilgi okuryazarlığı gibi alt boyutlardan oluştuğunu belirtmiştir. NCREL (2003) çalışmasında benzer şekilde, teknoloji okuryazarlığının dijital okuryazarlığın bir alt boyutu olduğunu ifade etmiştir. Çoklar ve Şahin (2014) ise çalışmasında bunun tam tersini iddia ederek bilgi okuryazarlığı, bilgisayar okuryazarlığı, dijital okuryazarlık ve internet okuryazarlığı gibi birçok okuryazarlığın "teknoloji okuryazarlığı" adı altında değerlendirilebileceğini belirtmiştir. Güneş ve Bahçivan (2017) ise daha da farklı bir görüş ortaya koyarak, dijital okuryazarlığa alternatif kavramlar olarak bilgi ve iletişim teknolojileri okuryazarlı̆̆ı, bilgisayar okuryazarlığı, medya okuryazarlığ kullanıldığını ifade etmiştir. Kapsamları bağlamında bakıldığında bu okuryazarlıkların farklılıklarını Tablo 6'daki gibi sunmak mümkündür.

Tablo 6. Kapsamları bağlamında okuryazarlıkların farklılıkları

\begin{tabular}{|c|c|}
\hline Teknoloji Okuryazarlığ & Dijital Okuryazarlık \\
\hline $\begin{array}{l}\text { Genel olarak bilgi, eleştirel düşünme ve karar } \\
\text { verme ve yetenekler boyutunda ele } \\
\text { alınmaktadır (Knieová vd., 2016; } \\
\text { Shackelford, 2007; Yiğit, 2011). }\end{array}$ & $\begin{array}{l}\text { Bilişsel, teknik (psikomotor) ve sosyo- } \\
\text { duyuşsal boyutlar açısından (Eshet, 2002; } \\
\mathrm{Ng}, 2012 \text { ) ele alınmaktadır. }\end{array}$ \\
\hline $\begin{array}{l}\text { Teknolojiye dair tasarım, tasarlanmış dünya } \\
\text { süreci yer almaktadır (Bacanak, } \\
\text { Karamustafaoğlu ve Köse, 2003). }\end{array}$ & Tasarım süreci yer almamaktadır. \\
\hline $\begin{array}{l}\text { Dijital araçların yasal, etik ve ahlaki } \\
\text { çerçevede kullanımı fazla } \\
\text { alınmamaktadır. }\end{array}$ & $\begin{array}{l}\text { Dijital araçların yasal, etik ve ahlaki } \\
\text { çerçevede kullanımı daha çok dikkate } \\
\text { alınmaktadır (Acar, 2015). }\end{array}$ \\
\hline
\end{tabular}

Tablo 6'ya göre teknoloji ve dijital okuryazarlıklarının farklılıkları incelendiğinde; teknoloji okuryazarlığında farklı olarak tasarım süreci yer alırken; dijital okuryazarlıkta ise yasal, etik ve ahlaki açıdan dijital araç kullanımına daha çok dikkat edilmektedir.

\section{Tartışma ve Sonuç}

Dijital okuryazarlık ve teknoloji okuryazarlığı özellikle son yıllarda gelişen ve birçok alana dahil olan dijital teknolojiler ile daha fazla gündeme gelmektedir. Ancak bu çalışmada da görüleceği üzere bu okuryazarlıkların kapsamı onyıllar öncesine (Petrina, 2003; Buckingham, 
2008) kadar dayanmaktadır. Bu nedenle bu çalışmada dijital ve teknoloji okuryazarlığı tarihsel süreci içerisinde karşılaştırmalı olarak incelenmiştir. Bu karşılaştırmada da görülmektedir ki dijital ve teknoloji okuryazarlığı kendi içerisinde benzerliklere sahip olduğu kadar farklılıkları da içermektedir. Bu çerçevede ilk noktayı dijital ve teknoloji okuryazarlığına yönelik tanımlamalarda görmekteyiz. Şöyle ki, teknoloji okuryazarlığı endüstriyel eğitim ve görsel işitsel eğitimle birlikte dijital okuryazarlığa göre daha eski bir kavram olsa da özellikle bilgisayarlaşma ile birlikte bu kavramların benzer tanımlamalar için kullanıldığı anlaşılmaktadır. Örneğin bu kavramların 1980'li yıllarda bilgisayar okuryazarlığ1 (Buckingham, 2008), 1990'lı ve 2000'li yıllarda ise bilgi ve iletişim teknolojileri okuryazarlı̆g (Leu ve Kinzer, 2000; Güneş ve Bahçivan, 2017) şeklinde tanımlandığ 1 görülmektedir. Bu durum, tarihsel süreç içerisinde bu okuryazarlıklardan hangisinin diğerinin alt boyutu olduğuna ya da bunların eş değer kavramlar olup olmadıklarına dair belirsizliklerin devam ettiğinin bir göstergesi olarak değerlendirilebilir. Hatta son yıllarda teknolojilerdeki hızlı ilerlemelere bağlı olarak bu okuryazarlıklara ilişkin seviyelendirmelerin yapılması da bu belirsizliklerin daha da artırabileceğinin bir göstergesi olarak dikkate alınabilir. Bu bağlamda literatür incelendiğinde Martin ve Grudziecki'nin (2006) yapmış oldukları çalışmada dijital okuryazarlığın üç seviyesinden bahsedildiği görülmektedir. Bunlardan birinci seviye dijital yetkinlik, ikinci seviye dijital kullanım ve üçüncü seviye ise dijital dönüşümdür. Dijital yetkinlik, temel becerilerden analitik seviyeye kadar hem alt hem de üst düzey düşünme becerilerini içerir. Dijital kullanım, dijital yetkinliğin alana özgü uygulamalarıyla ilgilidir ve dijital kullanım, yaratıcılığı kullanarak ilgili alanları dönüştürdüğünde dijital dönüşüm gerçekleşir.

Dijital ve teknoloji okuryazarlıklarının benzerlik ve farklılıklarına yönelik ikinci noktayı bu okuryazarlığa sahip bireylerin özelliklerinde görmekteyiz. Benzerlikler çerçevesinde değerlendirildiğinde benzerliğin ilgili teknolojileri kullanma becerisi çerçevesinde şekillendiği anlaşılmaktadır. Buna göre teknolojileri kullanma becerisinin etkin ve verimli kullanma, problemi çözebilme, değerlendirebilme ve karar verebilme gibi becerileri (Pearson ve Young, 2002; Bennett vd., 2009; Akkoyunlu ve Soylu, 2010; Yıldız, Kahyaoğlu ve Kaya, 2012; Al-Qallaf ve Al-Mutairi, 2016; Güneş ve Bahçivan, 2017) kapsadığ1 görülmektedir. Bu benzerliğin her iki okuryazarlık açısından bakıldığında araç gereç kullanımına yönelik bir gereksinimi barındırmasından kaynaklandığı değerlendirilebilir. Farklılıklar çerçevesinde değerlendirildiğinde ise teknoloji okuryazarı bireyler için belirlenen özelliklerin dijital okuryazarı bireyler için belirlenen özelliklere göre daha geniş bir bakış açısıyla dikkate alındığı anlaşılmaktadır. Şöyle ki teknoloji okuryazarlığında teknolojinin doğası, teknolojinin toplumla, bireyle ve çevreyle etkilişimi gibi (TfAAP, 1996; ITEA, 2000; Bacanak, Karamustafaoğlu ve Köse, 2003) daha geniş bir ilişki vurgulanırken dijital okuryazarlıkta daha çok dijital araçlar üzerinden ilgili süreçlerin gerçekleştirilmesi ve sorumlulukların yerine getirilmesi (Bakır, 2016; Tang ve Chaw, 2016; MEB, 2018) ya da dijital araçların yasal, etik ve ahlaki çerçevede kullanımı (Acar, 2015) vurgulanmaktadır. Bu sonuç, her iki okuryazarlık için yapılan tanımlamalardaki benzerlik ve farklılıkların bireylerin özellikleri için yapılan tanımlamalara da aynı şekilde yansıdığını göstermektedir.

Dijital okuryazarlık ve teknoloji okuryazarlılığının benzerlik ve farklılıklarına yönelik son noktayı bu okuryazarlıkların kapsamları bağlamında görmekteyiz. Dijital ve teknoloji okuryazarlığındaki benzerliğin özellikle son yıllarda bilgisayar okuryazarlığı, medya okuryazarlığı, bilgi okuryazarlığı gibi alanlar nedeniyle karmaşık bir şekilde iç içe geçmesinden (Bakır, 2016; Kurt vd., 2014; Ribble, Bailey ve Ross, 2004 ) kaynaklandığı 
değerlendirilebilir. Bunun en önemli göstergesi olarak ta artık dijital okuryazarlığın kazanılmadan toplum yaşamına katılabilmenin ve 21. yüzyılda yaşamak için gerekli olan bilgi ve beceriyi elde etmenin mümkün olamayacağı (Martin, 2005) ve benzer şekilde günümüz dijital çağında, öğrencilerin yaşamak, öğrenmek ve başarılı bir şekilde çalışabilmeleri için teknoloji okuryazarı olmaları gereksinimi (NCREL, 2003) gösterilebilir. Dijital ve teknoloji okuryazarlığındaki farlılık açısından ise en çok dikkati çeken noktanın tasarım ve tasarlanmış dünya anlayışının olduğu görülmektedir. Teknoloji okuryazarlığında dijital okuryazarlıktan farklı olarak tasarım süreci daha ön planda tutulmaktadır (Bacanak, Karamustafaoğlu ve Köse, 2003). Diğer bir nokta ise bu okuryazarlıkların özellikle son yıllardaki çalışmalarda birbirinin alt boyutları olarak konumlandırılmasıdır (Kıyıcı, 2008).

Sonuç olarak değerlendirildiğinde, ortaya çıan en önemli nokta kuşkusuz her iki okuryazarlığın artık çok boyutlu hale geldiğidir. Özellikle bu okuryazarlıklar üzerine yapılan çalışmalarla bu durumun daha da genişleyeceği öngörülebilir. Diğer bir önemli nokta ise teknoloyi içeren bu tür okuryazarlıkların (medya okuryazarlığı, bilgisayar okuryazarlığı vb.) kendi içlerinde benzerlik ve farklılıklara sahip olabileceğini açıkça göstermektedir. Dolayısıyla gerek dijital ve teknoloji okuryazarlığı olsun gerekse teknolojiyi içeren ilgili okuryazarlıklar olsun bunların olabildiğince bütüncül bir çerçevede incelenmesi ve değerlendirilmesi gerektiğini göstermektedir. Böylece ortak paydalar üzerinde birleşilebilecektir ve bu durum konunun eğitimini de kolaylaştırarak kavramların daha anlamlandırılabilir bir düzeye erişmesini sağlayacaktır. Ayrıca bu okuryazarlıkların gelecekte nasıl bir gelişme göstereceğini ve hangi noktalarda birleşip hangi noktalarda ayrılacağını öngörebilmek mümkün olabilecektir.

Bu çalışma yukarıda da belirtildiği üzere bazı sınırlıklara sahiptir. Bunlardan ikisi belli zaman aralığı ve belli anahtar kelimeler çerçevesinde çalışmanın şekillendiğidir. Dolayısıyla bu çok boyutlu durumu niteleyen özellikler bu sınırlılıklar çerçevesinde anlam kazanmaktadır. Benzer şekilde sınırlılıklarda da belirtildiği üzere bu çalışmada incelenen kaynaklar kendi metodolojik çalışmalarının sonuçlarını sunduklarından ortaya çıkan boyutların bağlamı da bu çerçevede sinırlı kalmaktadır.

\section{Öneriler}

$\mathrm{Bu}$ çalışma, sunduğu sonuçlar itibariyle ileride yapılabilecek çalışmalar için bazı önerilere sahiptir. Şöyle ki, öncelikle bu okuryazarlıkların basit bir değişken olarak görülmemesi gerektiği dolayısıyla lineer bir bakış açısıyla değilde çoklu bir bakış açısıyla çalışmalarda yer bulmaları gerektiği bir gerçektir. Böyle birbirleriyle bağlantılı konular olduğu düşünüldüğünde de artık ilgili çalışmalarda bu boyutların daha da önem kazanması gerektiği açıkça ortadadır. Özellikle dijital dönüşümün hızla gerçekleştiği günümüzde bu dönüşümün olası sonuçlarını görebilmeye çalışmak, dijital ve teknoloji okuryazarlığını ortak bir bağlamda değerlendirmekten geçtiğini söylemek anlamlı olacaktır. Bu bağlamda, ileride yapılacak ilgili çalışmalarda bu iki kavramın bir arada değerlendirilmesi ile çalışma sonuçlarında daha anlamlı çıtılar görülebileceğini söyleyebilmek mümkündür. Diğer bir açıdan bakıldığında bu çalışma karşılaştırmalı bir sunumu içermektedir ve böylece benzerlikler ve farklılıklar ortaya koymaktadır. Bu sonuç özel meta analizler için fırsatlar barındırmaktadır. Örneğin teknoloji içerğine sahip okuryazarlıklar üzerinde yapılacak meta analizlerle birbirinden bağımsız birden çok çalışmanın sonuçlarını birleştirme ve elde edilen araştırma bulgularının istatistiksel 
analizini yapma imkanı doğacaktır. Son olarak bu çalışmanın sunduğu bulgulardan ve sonuçlardan esinlenerek öğrenme araçlarının geliştirildiği ve değerlendirildiği araştırmalar önerilebilir. Örneğin dijital ve teknoloji okuryazarı bireylerin benzer ve farklı özelliklerini dikkate alınarak hazırlanabilecek somut ve dijital materyaller, e-öğrenme araçları ve içerik geliştirme üzerine çalışmalar yapılabilir.

\section{Kaynakça}

Acar, Ç. (2015). Anne ve babaların ilkokul ortaokul ve lise öğrencisi çocukları ile kendilerinin dijital okuryazarlıklarına ilişkin görüşleri. Ankara Üniversitesi Eğitim Bilimleri Enstitüsü, (Yayımlanmamış Yüksek Lisans Tezi), Ankara.

Akkoyunlu, B., \& Yılmaz Soylu, M. (2010). Öğretmenlerin sayısal yetkinlikleri üzerine bir çalışma. Türk Kütüphaneciliği, 24(4), 748-768.

Ala-Mutka, K. (2011). Mapping digital competence: Towards a conceptual understanding. Institute for prospective technological studies, Retrieved August 10, 2018 from http://ftp.jrc.es/EURdoc/JRC67075_TN.pdf.

Al-Qallaf, C. L., \& Al-Mutairi, A. S. R. (2016). Digital literacy and digital content support learning. The Electronic Library. https://doi.org/10.1108/el-05-2015-0076

Arastaman, G., Öztürk Fidan, İ., \& Fidan, T. (2018). Nitel araştırmada geçerlik ve güvenirlik: kuramsal bir inceleme. Yüzüncü Yıl Üniversitesi Ĕ̆itim Fakültesi Dergisi, 15(1), 37-75.

Aspers, P., \& Corte, U. (2019). What is qualitative in qualitative research. Qualitative Sociology, 42(2), 139-160. https://doi.org/10.1007/s11133-019-9413-7

Bacanak, A., Karamustafaoğlu, O., \& Köse, S. (2003). Yeni bir bakış: eğitimde teknoloji okuryazarlığı. Pamukkale Üniversitesi Ĕ̆itim Fakültesi Dergisi, 2 (14), 191-196.

Bakır, E. (2016). Sını öğretmeni adaylarının dijital vatandaşlık seviyelerinin dijital vatandaşlık alt boyutlarına göre incelenmesi. Karadeniz Teknik Üniversitesi Eğitim Bilimleri Enstitüsü, (Yayımlanmamış Yüksek Lisans Tezi), Trabzon.

Başkale, H. (2016). Nitel araştırmalarda geçerlik, güvenirlik ve örneklem büyüklügünün belirlenmesi. Dokuz Eylül Üniversitesi Hemşirelik Fakültesi Elektronik Dergisi, 9(1), 23-28

Bawden, D. (2008). Origins and concepts of digital literacy. In C. Lankshear, M. Knobel (Eds.), Digital literacies: Concepts, policies and practices (pp.17-32). New York: Peter Lang.

Bennett, W. L., Wells, C., \& Rank, A. (2009). Young citizens and civic learning: Two paradigms of citizenship in the digital age. Citizenship Studies, 13(5), 105-120. https://doi.org/10.1080/13621020902731116

Buckingham, D. (2008). Defining digital literacy: What do young people need to know about digital media? In C. Lankshear, M. Knobel (Eds.), Digital literacies: Concepts, policies and practices (pp.73-87). New York: Peter Lang.

Childers, S. (2003). Computer literacy: Necessity or buzzword? Information Technology and Libraries, 22(3), 100-104. 
Çoklar, A. N., \& Şahin, Y. L. (2014). Öğrencilerin gözüyle teknoloji okuryazarlığı: Nedir, neredeyiz, aile ve çocuklar için neler yapmalı? Turkish Online Journal of Qualitative Inquiry, $5(2), 27-34$.

Condy, J., Chigona, A., Gachago, D., \& Ivala, E. (2012). Pre-service students' perceptions and experiences of digital storytelling in diverse classrooms. Turkish Online Journal of Educational Technology, 11(3), 278-285.

Corbin, J., \& Strauss, A. (2008). Basics of qualitative research: Techniques and procedures for developing grounded theory (3rd Ed.). Thousand Oaks, Ca: Sage.

Crowe, A. R. (2006). Technology, citizenship, and the social studies classroom: Education for democracy in a technological age. International Journal of Social Education, 21(1), 111-121.

Dede, C. (2010). Comparing frameworks for 21st century skills. In J. Bellanca, R. Brandt (Eds.), 21st century skills: Rethinking how students learn (pp.51-76). America.

Eshet, Y. (2002). Digital literacy: A new terminology framework and its application to the design of meaningful technology-based learning environments. In P. Kommers, G. Richards (Eds.), Proceedings of world conference on educational multimedia, hypermedia and telecommunications pp (493-498). Chesapeake, VA: AACE.

Eshet-Alkalai, Y. (2004). Digital literacy: A conceptual framework for survival skills in the digital era. Journal of Educational Multimedia and Hypermedia, 13(1), 93-106.

Fereday, J., \& Muir-Cochrane, E. (2006). Demonstrating rigor using thematic analysis: A hybrid approach of inductive and deductive coding and theme development. International Journal of Qualitative Methods, 5(1), 80-92.

Gilster, P. (1997). Digital literacy. New York: Wiley.

Guba, E. G., \& Lincoln, Y. S. (1982). Epistemological and methodological bases of naturalistic inquiry. Educational Communication and Technology Journal, 30 (4), 233-252.

Güneş, E., \& Bahçivan, E. (2017). A mixed research-based model for pre-service science teachers' digital literacy: Responses to "which beliefs" and "how and why they interact" questions. Computers \& Education, 118, 96-106.

Hamutoğlu, N. B., Güngören, Ö. C., Kaya Uyanık, G., \& Gür Erdoğan, D. (2017). Dijital okuryazarlık ölçeği: Türkçe’ye uyarlama çalışması. Ege Eğitim Dergisi, 18(1), 408- 429.

Herman, N. D. Maknun, J. Barliana, M. S., \& Mardiana, R. (2018). Technology literacy level of vocational high school students. Advances in Social Science, Education and Humanities Research, 299, 519-522.

ITEA (International Technology Education Association) (2000). Standards for technological literacy: Content for the study of technology. Reston, VA: Author.

Kıyıcı, M. (2008). Öğretmen adaylarının sayısal okuryazarlık düzeylerinin belirlenmesi. Anadolu Üniversitesi Eğitim Bilimleri Enstitüsü, (Yayınlanmamış Doktora Tezi), Eskişehir.

Knieová, V., Janovec, J., Kroufek R., \& Chytrý V. (2016). Affective dimension of technological literacy. L. G. Chova, A. L. Martínez \& I. C. Torres (Eds.). 9th Annual International Conference of Education, Research and Innovation, (pp. 590-596). Iated Academy, Seville, Spain. 
Kurt, A. A., Orhan, D., Yaman, F., Solak, M. Ş., \& Türkan, F. (2014). Bilgi ve iletişim teknolojileri ışığında Türkiye'de yapılan okuryazarlık çalışmalarındaki eğilim. Eğitim Teknolojileri Araştırma Dergisi, 5 (2), 1-21.

Leaning, M. (2019). An approach to digital literacy through the integration of media and information literacy. Media and Communication, 7 (2), 4-13.

Leu, D. J., \& Kinzer, C. K. (2000). The convergence of literacy instruction with networked technologies for information and communication. Reading Research Quarterly, 35(1), 108-127.

Martin, A. (2005). DigEuLit - A European framework for digital literacy: A progress report. Journal of e-Literacy, 2(2),130-136.

Martın, A., \& Grudziecki, J. (2006). DigEuLit: Concepts and tools for digital literacy development. Innovation in Teaching and Learning in Information and Computer Sciences, 5(4), 249-267.

Mc-Millan, S. (1996). Literacy and computer literacy: Definitions and comparisons. Computer $\mathcal{E}$ Education, 27(3), 161-170.

Media Awareness Network. (2010). Digital literacy in Canada: From inclusion to transformation. A submission to the digital economy strategy consultation, Retrieved February 2, 2018, from http://www.mediaawareness.ca/english/corporate/media_kit/digital_literacy_paper_pdf/d igitalliteracypaper.pdf

MEB (Milli Eğitim Bakanlığı) (2018). Fen bilimleri dersi öğretim programı (ilkokul ve ortaokul 3, 4, 5, 6, 7. ve 8. sinıflar). Ankara: Talim ve Terbiye Kurulu Başkanlığı.

Merriam, S. B. (1998). Qualitative research and case study applications in education. San Francisco: Jossey-Bass.

National Research Council Committee on Information Technological Literacy (1999). Being fluent with information technology. Washington, D.C.: National Academy Press.

$\mathrm{Ng}, \mathrm{W}$. (2012). Can we teach digital natives digital literacy? Computers $\mathcal{E}$ Education, 59(3), 10651078.

Norton, P., \& Wiburg, K. M. (1998). Teaching with technology. New York: Harcourt Brace.

Patton, M. Q. (2002). Qualitative research \& evaluation methods. London: Sage Publication.

Petrina, S. (2003). The educational technology is technology education manifesto. Journal of Technology Education, 15(1), 64-74.

Perdana, R., Yani, R., Jumadi, J., \& Rosana, D. (2019). Assessing students' digital literacy skill in senior high school Yogyakarta. JPI, 8(2), doi: 10.23887/jpi-undiksha.v8i2.17168

Pearson, G., \& Young, A. T. (2002). Technically speaking: Why all Americans need to know more about technology. Washington: National Academies Press.

Ribble, M. S., \& Bailey, G. D. (2007). Digital citizenship in schools. Eugene: International Society for Technology in Education.

Ribble, M. S., Bailey, G. D., \& Ross, T. W. (2004). Digital citizenship: Addressing appropriate technology behavior. Learning \& Leading with Technology, 32(1), 6-11. 
Shackelford, R. (2007). Technological literacy: A new basic for inclusion in the university's core curriculum. University College Cork, Ireland.

Tang, C. M., \& Chaw, L. Y. (2016). Digital literacy: A prerequisite for effective learning in a blended learning environment? The Electronic Journal of e-Learning, 14 (1), 54-65. Retrieved from http://www.ejel.org/main.html

Techataweewan, W., \& Prasertsin, U. (2018). Development of digital literacy indicators for Thai undergraduate students using mixed-method research. Kasetsart Journal of Social Sciences, 39, 215-221.

TFAAP (Technology for All Americans Project) (1996). Technology for all Americans: A rationale and structure for the study of technology. International Technology Association, Reston, VA.

NCREL (The North Central Regional Educational Laboratory) (2003). Engauge 21st century skills: Literacy in the digital age. Retrieved July 2, 2018, from http://pict.sdsu.edu/engauge21st.pdf.

Timur, B., Timur, S., \& Akkoyunlu, B. (2014). Öğretmen adaylarının sayısal yetkinlik düzeylerinin belirlenmesi. Muğla Sıtkı Koçman Üniversitesi Sosyal Bilimler Enstitüsü Dergisi, $33,41-59$.

Üstündağ, M. T., Güneş, E., \& Bahçivan, E. (2017). Turkish adaptation of digital literacy scale and investigating pre-service science teachers' digital literacy. Journal of Education and Future, 12, 19-29.

Wang, K. F. S. (2003). The development of benchmarks and the selection of appropriate methods to assess technological literacy portion of the natural science and living technology curriculum as required by the 2000 national curriculum guidelines of the Republic of China (Taiwan), The Ohio State University, (Unpublished Doctoral Thesis), Ohio.

Yıldız, Ç., Kahyaoğlu, M., \& Kaya, F. M. (2012). Siirt ilindeki ortaöğretim öğrencilerinin sayısal okuryazarlık düzeylerinin cinsiyet, sınıf ve öğrenim gördüğü lise türüne göre farklılaşmasının incelenmesi. Uşak Üniversitesi Sosyal Bilimler Dergisi, 5(3), 81-95.

Yiğit, E. Ö. (2011). Sosyal bilgiler öğretmen adaylarının teknoloji okuryazarlığı düzeylerinin ve teknoloji ile bütünleştirilmiş sosyal bilgiler öğretimine yönelik görüşlerinin belirlenmes. Marmara üniversitesi eğitim bilimleri enstitüsü (Yayınlanmamış Doktora Tezi), İstanbul.

Yin, R. K. (2018). Case study research and applications: Design and methods (Sixth Edition). Thousand Oaks, California: Sage Publications. 